\title{
CLINICAL MANAGEMENT OF VARIOUS TYPES OF DEVIATED NASAL SEPTUM
}

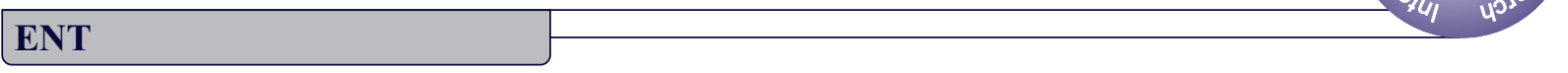

Dr. Shambhu MBBS, M.S. (ENT), Senior Resident, Department of ENT, Vardhman Institute of Medical Sharan Gupta* Dr. [Prof.] Satish Kumar Sciences (VIMS), Pawapuri, Nalanda, Bihar.*Corresponding Author

\section{Dr. Debarshi Jana \\ Young Scientist (DST) Institute of Post-Graduate Medical Education and Research,
A.J.C. Bose Road, Kolkata-700020, West Bengal, India.

\section{ABSTRACT} \\ Deviated nasal septum is a common condition, which is quite often asymtomatic, but may present with persistent morbidity in some. In this prospective cross sectional study, 100 patients with deviated nasal septum were included who were symptomatic. 48 patients needed surgical intervention while 52 were managed conservatively. Results were compared on follow up. $96 \%$ cases reported improvement in nasal obstruction post surgery, compared to $79 \%$ following conservative management.}

MBBS, M.S. (ENT), Professor and Head of Department, Department of ENT, Vardhman Institute of Medical Sciences (VIMS), Pawapuri, Nalanda, Bihar.

\section{KEYWORDS}

\section{INTRODUCTION}

The nasal septum is an osseo-cartilaginous structure in the middle of the nose which separates the nasal cavity into right and left sides. Deviations of this nasal septum is a common condition encountered in clinical practice. These septal deformities may be congenital or developmental or they may have a traumatic etiology. A person with mild septal deviation may be completely free of symptoms and may even be unaware of its presence. On the other hand, septal deviation may present with various symptoms such as persistent nasal obstruction, headache, snoring, posterior nasal drip etc.

The nasal septum has many important functions including separating the nasal airway into two distinct chambers, support of dorsum of nose and maintaining the shape of the columella and tip of the nose. Any obstruction to airflow can cause problems in humidification of air, olfaction and phonation. Chronic sinus disease may also be seen as a result of nasal septal deviation. It is essential to evaluate every patient presenting with nasal obstruction and deviated nasal septum with nasal endoscopy and CT scan of nose and paranasal sinuses to rule out coexisting pathology like nasal polyp, inferior turbinate hypertrophy, concha bullosa, chronic sinusitis.

\section{METHODS AND MATERIALS}

This study was conducted under the Department of ENT, Vardhman Institute of Medical Sciences, Pawapuri, Nalanda, Bihar for a period of 1 year from November 2019 to October 2020.

A cross sectional study was done on patients with deviated nasal septum attending in the outpatient department of ENT department of VIMS.

Prior written and informed consent was taken from all participants in the study.

100 patients of deviated nasal septum presenting with nasal obstruction were included.

Patients with deviated nasal septum presenting with nasal obstruction were included in the study according to the following criteria :

Inclusion criteria

- Patients above 12 years age

- Patients of deviated nasal septum presenting with nasal obstruction

- Patients giving consent for the study.

Exclusion criteria

- Patients below 12 years age

- Patients with previous nasal surgery

- Patients having deviated nasal septum but not complaining of nasal obstruction

- Patients having surgery for deviated nasal septum combined with other surgery like sinus surgery etc.

- Patients not giving consent were excluded.
In septoplasty, usually mucosal flap is raised on the concave side for excision of septal cartilage and bone. Techniques such as detaching septal osseo-cartilaginous junction and scoring of concave side may be used. Deviated septum can be kept in a straight line if it is splinted against a graft such as bone from perpendicular plate of ethmoid or vomer.

Mattress sutures may be used to control the septal curvature.

Endoscopic septoplasty can be done using endoscopes for better visualisation of more cephalic deformities.

External approach septoplasty is suitable in cases with dorsal L strut deformity, to improve surgical access.

In cases of severely fractured or deformed septum, correction and reconstruction can be done by extracorporeal septoplasty.

\section{RESULTS}

In our study, total 100 patients were included out of which 55 were male and 45 were female patients.

6 patients were in the age group 12-20 years, 47 in the age group of 21 30,31 in 31-40 years group, 14 patients in 41-50 age group and 2 patients in 51-60 years group.

In 10 patients anterior deviation was seen and in 6 patients there was posterior deviation. C shaped deviation was seen in 42 patients, 18 patients had S shaped deviation, 12 had caudal dislocation. Thickened septum was seen in 4 patients while 36 had spurs.

In our study 39 patients had right sided deviation, 43 had left sided deviation while 18 patients had deviation on both sides ( $\mathrm{S}$ shaped deviation)

In our study most of the patients presented with unilateral nasal obstruction(66), followed by posterior nasal discharge(39), headache(36), bilateral nasal obstruction(34), sneezing(22), hyposmia(18), snoring(11) and epistaxis(9).

48 of our patients needed surgical intervention while 52 were managed conservatively.

Submucosal resection (SMR) was done in 36 patients while septoplasty was done in 12 .

Table 1 : Post operative complications

\begin{tabular}{|c|c|c|c|}
\hline Complication & Surgery Type & No. of patients & Percentage \\
\hline \multirow{2}{*}{ Haematoma } & SMR & 2 & $5.5 \%$ \\
\cline { 2 - 4 } & Septoplasty & 0 & $0 \%$ \\
\hline
\end{tabular}




\begin{tabular}{|c|c|c|c|}
\hline \multirow{2}{*}{ Bleeding } & SMR & 16 & $44.4 \%$ \\
\cline { 2 - 4 } & Septoplasty & 2 & $16.67 \%$ \\
\hline \multirow{2}{*}{ Septal abscess } & SMR & 0 & $0 \%$ \\
\cline { 2 - 4 } & Septoplasty & 0 & $0 \%$ \\
\hline \multirow{2}{*}{ Perforation } & SMR & 2 & $5.5 \%$ \\
\cline { 2 - 4 } & Septoplasty & 0 & $0 \%$ \\
\hline \multirow{2}{*}{ Deformity } & SMR & 0 & $0 \%$ \\
\cline { 2 - 4 } & Septoplasty & 0 & $0 \%$ \\
\cline { 2 - 4 } & SMR & 0 & $0 \%$ \\
\hline \multirow{2}{*}{ Adhesion } & Septoplasty & 0 & $0 \%$ \\
\cline { 2 - 4 } & SMR & 3 & $0 \%$ \\
\hline
\end{tabular}

Table 2 : Post surgery Results

\begin{tabular}{|l|l|l|l|}
\hline Symptoms & Improved & $\begin{array}{l}\text { Not } \\
\text { Improved }\end{array}$ & $\begin{array}{l}\text { Percent } \\
\text { Improved }\end{array}$ \\
\hline Nasal obstruction & 46 & 2 & $96 \%$ \\
\hline Headache & 11 & 5 & $69 \%$ \\
\hline Snoring & 6 & 3 & $67 \%$ \\
\hline Posterior Nasal discharge & 9 & 3 & $75 \%$ \\
\hline Epistaxis & 6 & 1 & $86 \%$ \\
\hline Sneezing & 7 & 3 & $70 \%$ \\
\hline Hyposmia & 6 & 4 & $60 \%$ \\
\hline
\end{tabular}

Table 3 : Post Medication Results

\begin{tabular}{|l|l|l|l|}
\hline Symptoms & Improved & Not Improved & Percent Improved \\
\hline Nasal obstruction & 41 & 11 & $79 \%$ \\
\hline Headache & 11 & 9 & $55 \%$ \\
\hline Snoring & 0 & 2 & $0 \%$ \\
\hline Posterior Nasal & 22 & 5 & $81 \%$ \\
\hline Epistaxis & 2 & 0 & $100 \%$ \\
\hline Sneezing & 10 & 2 & $83 \%$ \\
\hline Hyposmia & 6 & 2 & $75 \%$ \\
\hline
\end{tabular}

\section{DISCUSSION}

Patients presenting with symptomatic deviated nasal septum were included in the study. The different types of presentation of deviated nasal septum were studied and the management of each case, either surgical or conservative was documented.

Complete history and examination of each patient was done followed by necessary investigations including CT scan and nasal endoscopy.

Study population was analysed on the basis of demography, presenting symptoms, type of deviated nasal septum and type of management.

In our study, most of the patients were male(55\%), which was similar to the study by Mladina et al where nasal septal deviation was found to be higher in males. Most patients were in the age range of 21-30 years.

Nasal obstruction was the symptom found in all cases, followed by nasal discharge and headache.

Oliveira et al in their study found rhinitis to be most commonly associated with septal deviation.

93\% of the patients had headache as the predominant symptom in another study by Shoib et al, followed by nasal discharge $(63 \%)$.

In another study by Singh, headache was the predominant symptom seen in over $80 \%$ of the cases, while $77 \%$ of them had nasal obstruction.

C-shaped deviation was found most commonly in our study (42\%), which was similar to that found in the study by Moorthy et al. Other types of deviation found were S-shaped deviation, caudal dislocation, anterior vertical deviation, posterior vertical deviation, horizontal spurs.

Among 52 patients managed conservatively, only 41 achieved relief from nasal obstruction after 3 months, while the others had recurrence of symptoms after initial period of relief, similar to results found by Eccles et al. None of the patients reported side effects from use of topical nasal decongestants and oral antihistamines.

$55 \%$ of patients had relief from headache following medications and $81 \%$ reported decrease in posterior nasal discharge.

Of the 48 patients managed with surgery, 46 had relief from nasal obstruction after a period of 3 months, which was similar to results obtained by Stewart et al, Bugten et al and Buckland

In the surgical group, $69 \%$ of patients had relief from headache following surgery, which was similar to results from Low and Stewart.

Septal perforation was found in 2 cases out of 48 operated patients, which were asymptomatic and was less than found in studies by Iqbal et al and Alamri et al. Most commonly, perforations result from traumatic elevation of the mucosal flaps with opposing tears in the flap on either side. Careful and meticulous elevation of the mucosal flaps is the key to prevention as is making an effort to close any mucosal tears at the end of surgery.

Recurrence of deformity was not found in the follow up period unlike that reported in literature where recurrence was found in upto $6 \%$ of cases.

Adhesions were found in post-operative follow up in 3 cases.

Excessive bleeding was the most frequent complication in our study, which is similar to findings reported in other studies.

The rate of local infection and septal abscess after septoplasty ranges from 0.4 to $12.0 \%$ as reported in literature, but were seen in none of our cases.

The overall rate of significant change in the cosmetic appearance of the nose after septoplasty has been reported between $0.4-3.4 \%$, but was seen in none of our cases.

Anosmia or hyposmia is most often temporary and is due to edema. Permanent anosmia resulting from nasal surgery, as reported in the literature is uncommon $(0.3-2.9 \%)$. Temporary anosmia was seen in 2 cases in our study.

Other infectious complications such as meningitis, brain abscess, cavernous sinus thrombosis and endocarditis are extremely rare.

Cerebrospinal fluid (CSF) rhinorrhea after septoplasty is a rare, but serious complication. It can be avoided by taking care when resecting high deviations. This was not seen in our study.

Limited studies have been done to investigate the rate of dental anesthesia of the upper incisors after septoplasty surgery, but it is a potential complication.

Ocular complication, including blindness, are very rare, but can occur The theory for complete visual loss after septoplasty is that when epinephrine is injected under pressure into the mucosa of the septum or tissue surrounding the inferior turbinate, there is a risk of a retrograde flow through the anterior ethmoidal artery into the ophthalmic artery, which can cause vasospasm of the end arteries to the optic nerve and retina. This hypo perfusion can induce optic nerve neuropathy.

Atrophic rhinitis has been attributed to overly aggressive turbinate resection with chronic symptoms of nasal crusting, mucosal atrophy and nasal congestion. Empty nose syndrome is a similar condition more specifically referring to the symptoms of paradoxical nasal congestion. These rare complications were not seen in our study.

Data was analysed using chi-square test to test for statistical significance of the findings.It was found that symptoms of nasal obstruction improved in 41 out of 52 patients treated with medications compared with 46 out of 48 treated with surgery $(\mathrm{p}<0.05)$, which shows statistical significance in favour of surgical management. However, improvement in headache $(\mathrm{p}=0.4003)$, posterior nasal discharge $(p=0.6436)$ and sneezing $(p=0.4574)$ did not show significant variation between medical or surgical management.

Comparing SMR and septoplasty, post operative bleeding was found in $16 / 36$ cases of SMR and $2 / 12$ cases in septoplasty $(\mathrm{p}=0.0851)$ which did not show statistical significance in relation to type of surgery. However, 2 cases of septal hematoma, 3 cases of septal adhesions and 2 cases of septal perforations were seen only in SMR cases, and none in the 12 septoplasty cases.

Post operative bleeding in all cases were minor and managed with 
intravenous tranexamic acid, topical hemocoagulase solution and additional packing without removing the septal clips. Two cases of septal hematoma were treated by removal of septal clips and drainage in the operation theatre. Three cases of septal adhesions were seen, which were managed by adhesion breakdown under local anaesthesia in the operation theatre followed by nasal packing for 24 hours. Two cases of septal perforation were seen which were managed conservatively

\section{CONCLUSION}

Deviated nasal septum is a very common condition in our area, which can occasionally cause severe symptoms such as nasal obstruction and rhinitis. Most of the patients in our study had $\mathrm{C}$ shaped deviated septum. This study highlights the prevalence and the symptoms of nasal septum deviation and their management.

It was found that medical management using topical nasal decongestants and antihistamines provide only temporary relief to symptoms which recur again.

Surgical management gave comparatively better control of symptoms whether it was sub mucosal resection or septoplasty. However, post operative complications were found to be less in septoplasty cases. Complications can be kept to a minimum with good post-operative care.

The sample size of the present study was comparatively small with less time for follow up so further studies must be performed to arrive at a proper conclusion regarding the relevance of these findings.

\section{REFERENCES}

1. Alamri AA, Alsulami AA, Almahyawi RA, Abushal RA, Fida AR. Predicting factors of Alamri AA, Alsulami AA, Almahyawi RA, Abushal RA, Fida AR. Predicting factors of
recurrent deviated nasal septum after primary septoplasty in Jeddah, Saudi Arabia. Egypt J Otolaryngol 2018;34:266-71

2. Buckland JR, Thomas S, Harries PG. Can the sinonasalout come test (SNOT-22) be used as a reliable out come measure for successful septal surgery? Clinical Otolaryngology Allied Sci.2003 Feb;28(1):43-7

3. Bugten V, Nilsen AH, Thorstensen WM, Moxness MH, Amundsen MF, Nordgård S Quality of life and symptoms before and after nasal septoplasty compared with healthy individuals. BMC Ear Nose Throat Disord. 2016;16:13

4. Eccles, R., Eriksson, M., Garreffa, S., \& Chen, S. C. (2008). The Nasal Decongestant Effect of Xylometazoline in the Common Cold. American Journal of Rhinology, 22(5), Effect of Xylometazoline in the Common Cold. American Journal or Rhinology, 22(5),

5. Fiser A. Changes of olfaction due to aesthetic and functional nose surgery. ActaOtorhinolaryngol Belg. 1990

6. Iqbal A M, Nabil R .Complications of the surgery for deviated Nasal Septum.JColl Physicians Surg Pak. 2003;13:565-568

7. Iqbal A M, Nabil R .Complications of the surgery for deviated Nasal Septum.JColl Physicians Surg Pak. 2003;13:565-568.

8. Ketcham AS, Han JK. Complications and management of septoplasty. OtolaryngolClin NAm. 2010;43:897-904.

9. Mladina R, "The role of maxillar morphology in the development of pathological septal deformities," Rhinology, vol. 25, no. 3, pp. 199-205, 1987.

10. Moorthy, P., Kolloju, S., Madhira, S. and Jowkar, A. (2014) Clinical Study on Deviated Nasal Septum and Its Associated Pathology. International Journal of Otolaryngology and Head \& Neck Surgery, 3, 75-81. doi: 10.4236/ijohns.2014.32016

11. Oliveira AKP, Júnior EE, Santos LV, Bettega G, Mocellin M. Prevalence of Deviated Nasal Septum in Curitiba, Brazil. Int Arch Otorhinolaryngol. 2005;9(4):288-92.

12. Onerci TM, Ayhan K, Oğretmenoğlu O. Two consecutive cases of cerebrospinal fluid rhinorrhea after septoplasty operation. Am J Otolaryngol. 2004;25:354-356.

13. Randall KL, Hawkins CA. Antihistamines and allergy. AustPrescr. 2018;41(2):41-45. doi:10.18773/austprescr.2018.013

14. Randall KL, Hawkins CA. Antihistamines and allergy. AustPrescr. 2018;41(2):41-45. doi:10.18773/austprescr.2018.013

15. Rettinger G, Kirsche H. Complications in septoplasty. Facial Plast Surg. 2006;22:289-297.

16. Shoib SM, Viswanatha B. Association between Symptomatic Deviated Nasal Septum and Sinusitis: A Prospective Study. Res Otolaryngol. 2016;5(1):1-8.

17. Singh I,Sherstha A, Gautam D, Ojasvini.ChronicRhinosinusitis and Nasal Polyposis in Nepal.ClinRhinol:Int J. 2010;3(2):87-91.

18. Stammberger H. History of rhinology: Anatomy of the paranasal sinuses. Rhinology 1989;27:197-210 